\section{THE VERTEBRATE SKELETON}

GELETAL archetypes, and "theories of the skull," $\rightarrow$ have of late years gone much out of fashion. The view which made each man a potential Briareus as to limbs, seems itself to be considered as no longer having a leg to stand upon. The fortress of the "Petrosal" has long been carried by assault, and is peaceably and securely occupied; and although we have had lately a brilliant passage of arms apropos of the "auditory ossicles" from which the unlucky Sauropsida retired with broken "hammers" and diminished "anvils ;" yet the once widespread interest in skeletal controversies seems to have long subsided. The old war-cries are no longer heard, the question "Is the post-frontal a parapophysis?" falls on indifferent or averted ears, and we fear that even not a few of our anatomists call into daily functional activity a mandible, to the true nature and homologies of which they are comparatively indifferent.

What was the surprise of some, then, who last year witnessed, in the theatre of the Royal College of Surgeons, an unlooked-for resurrection. Some rubbed their eyesconid they have had a long sleep, and was it still the year I 849 instead of 1869 ? A quasi-vertebrate theory of the skull once more! Again an exposition of cranial hœmal arches!

$$
\text { " Jam redit et Virgo, redeunt Saturnia regna." }
$$

But yet in justice it must be said that it was by no means the reproduction of an old or familiar system. The views propounded were in some respects as novel as striking; while in spite of this a careful re-statement of assertions made in the first year of the last Hunterian professorship showed how subordinate after all were the changes made, and how trifling the modifications required as to the statements of that first year. Nor in fact was any new archetypical idea of the whole vertebrate skeleton distinctly proposed for acceptance, though the serial relationship of certain inferior arches was clearly demonstrated, and a striking suggestion made concerning the most anterior of them.

But some ideal conception of the vertebrate skeleton as a whole is a necessity for anyone who proposes to extend his osteological labours over several classes, and provided such a conception be a simple "generalised expression of observed facts," no one has a right to complain of its introduction. What best conception then of this kind can be now supplied from the accumulated labours of successive osteologists?

As the points of exit from the skull of the cranial nerves supply the best fixed points for determining special cranial homologies, so probably the arrangement of the nervous system as a whole will supply the handiest key to the explanation of skeletal difficulties.

In the Hunterian Lectures of 1869 , the nervous system was treated in a new way, and one by which the sympathetic system lost its isolation, and was called in to take its morphologically important part in the general system of spinal nerves. The embryonic condition being referred to (with ascending dorsal plates and descending ventral-plates-the latter bifurcating to enclose the pleuroperitoneal space between their outer and inner laminæ), each spinal nerve of the trunk was represented as sending one branch upwards into the dorsal plate, another downwards into the outer lamina of the ventral plate (abdominal and intercostal nerves), and another, also downwards, but into the inner lamina of the ventral plate, the collection of these latter internal nerves with their serial homologues forming the sympathetic system. In addition to these, a branch was represented as running directly outward towards the skin, above the external descending branch. Now, such being the condition of the nervous system, what might we a priori expect to find in the skeleton? Surely we might expect to find-rst, Parts related to the dorsal laminæ (epaxial); 2nd, Parts related to the external ventral laminæ (paraxial), and $3 \mathrm{rd}$; Parts related to the internal ventral laminæe (hypaxial). To the first category would belong the neural arches, \&c. ; to the second, the transverse processes, ribs, and steruum; to the third would belong those skeletal structures, if such there are, within the pleuro-peritoneal cavity or medianly situated beneath the vertebral column.

But as to the nerves passing directly outwards above the external descending ones, are there any skeletal structures to answer to them?

Now, fishes present us sometimes with a double series of ribs, whereof the upper strike out towards the skin, while the lower tend to enclose the abdominal cavity. In tailed Batrachians we have two superimposed transverse processes to which a bifurcating Y-shaped rib articulates, and this rib sometimes bifurcates distally also. In mammals we have a rib essentially similar as to its proximal end, but one branch of the $\mathrm{Y}$ is diminished into a tubercle, which, however, meets a transverse process. Can it be, then, that our own ribs are morphologically double, and that their upper proximal parts together with the fascia ascending from triem to bound externally the erector spince, are homologous with the upper series of the ribs of fishes?

But what are the hypaxial structures, and first, what parts of the skeleton are within the pleuro-peritoneal cavity or are serially homologous with parts so situated? Here an important modification seems necessary in the views given out by Professor Huxley in 1869. He demonstrated unanswerably that the branchial arches are, as Professor Goodsir considered them, thoroughly homologous with the hyoidean and mandibular arches, and not only this, but he also suggested-what was as novel as important - that the trabecula craniz may be the foremost members of the same group of parts. He considered, however, that all these parts were costal in their nature. Now, accepting this view as far as regards the serial homology of the branchial arches with parts more anterior, it is nevertheless here submitted that the branchial arches should be considered parts within the pleuroperitoneal cavity, and this because the heart lies outside them, and the great vessels (which even in man have reflected on them a continuation of the pericardium) extend along their outer sides. It is contended, then, that these arches are hypaxial parts, and, if this is so, then the hyoidean, mandibular, palato-quadrate, and trabecular structures, as they are serially homologous with the branchial arches, must be hypaxial also. If so, the nerves which accompany them (the vagus, \&c.) must be serially homologous with the sympathetic nerves of the trunk, and, indeed, this view was put forward by Professor Huxley in the lectures referred to. Are there, then, no 
true representatives of costal arches in this part of the frame? I think that the external branchial cartilages of sharks and the branchial basket of the Lamprey will be found to be such, and therefore to belong to a quite different category from that to which the branchial arches of osseous fishes pertain.

Again those azygos processes which descend from beneath the vertebral column in the region of the trunk, must be in the line of origin and suspension of the internal lamellæ of the ventral plates of the embryo, and being related to them may be deemed to be hypaxial parts also. Their serial homologues often bifurcate, and are repeated serially in the caudal region by processes or distinct ossicles (chevron bones) protecting the caudal vessels, and which I deem to be hypaxial also. Professor Goodsir has demonstrated that in the crocodile such parts, at the root of the tail, lie within the backward prolongation of the abdominal cavity, and the chcvron bones or processes beyond that cavity in the same individual, are clearly the serial homologues of those within it.

According to this view then, the vertebrate axial skeleton in its most generalised expression consists of an antero-posteriorly extended axis, bearing above it (I) a cylinder of cpaxial parts, for the protection of the cerebrospinal centres. This cylinder expands anteriorly, and has intercalated three sets of sense capsules, olfactory, optic, and auditory. Everything, whatsoever it be, outside the anterior end of this cylinder (the cranial capsule) is morphologically outside the skull, and therefore in such an essentially extornal position is the sella turcica, the anterior communicating artery, \&c.

2. From the axis of the skeleton diverge on each side more or less bifid paraxial parts, tending to protect or surround the visceral cavity, or homologous with parts which do so tend.

3. From the same axis descend hypaxial parts, which parts attain their maximum of size and importance towards the two ends of the skeleton. At the anterior end they by their varied degree of development and coalescence, build up the frame-work of the face, the jaws, and the hyoidean structures.

To this axial skeleton is added, in completely developed forins, two limb-girdles, each consisting of one upwardly and two inwardly and downwardly directed parts on each side. Two limbs, bilaterally symmetrical, are attached to each girdle, and a serial symmetry, bone answering for bone, exists between the anterior and posterior limbs of each side.

Can the skeleton structure of these limbs be expressed in yet simpler terms? Professor Gegenbaur has attempted very ingeniously so to express it, considering the $\operatorname{limb}$ bones as differentiations of primitive similar offshoots from a chain of marginal fin bones or cartilages. But much as one would naturally wish to accept so tempting a theory, two obstacles at present oppose themselves. One is the presence of a radial ossicle answering to the pisiforme of the ulnar side. The other is the occasional presence, in fossil forms, of at least one whole chain of such ossicles. So that at present we can hardly in this respect venture upon a more generalised view of the skeleton than the one here adopted.

This conception of the vertebrate skeleton takes little account of the mode of origin of skeletal parts-whether exogenous or autogenous, or of their segmented or unsegmented condition. But such considertaions have been neglected deliberately from a conviction of the completely subordinate importance of such conditions. The views here stated suggested themselves during the study of the skeleton as it exists in tailed batrachians; they have elsewhere been given at length, and their defence attempted, but it has been thought that a brief statement of then here might not be altogether unacceptable to some who are engaged in osteological inquiries.

ST. George Mivart

\section{HOOKER'S BRITISH FLORA}

The Student's Flora of the British Islands. By J.D. Hooker, C.B., M.D., F.R.S., Director of the Royal Gardens, Kew. (London: Macmillan and Co., 1870.) NOTWITHSTANDING the number of British Floras 1 already in existence, field-botanists have long lamented the want of a text-book combining all the requisites for out-of-door work, unquestionable accuracy, clearly-expressed definitions, a good arrangement, and a portable form. Although the hand-books we have hitherto used have possessed one or other of these features in an eminent degree, no one has yet succeeded in uniting them. For accomplishing this difficult task the best thanks of every British botanist are due to Dr. Hooker. The publication in quick succession of several works with a similar scope, may be taken as an indication of a reviving interest in British botany. Thirty years since, when the Linnean system of classification was still in use, a sufficient acquaintance with plants to enable anyone to give the Latin names of the species of their own districts was a fashionable acquirement, especially with ladies. The knowledge, however, was extremely superficial ; it consisted mainly in counting the number of stamens and of pistils, so as to determine the class and order, and of observing the trivial specific characters of the foliage, colour and size of the flowers, \&c., and was unaccompanied with the least real acquaintance with structural or physiological botany. An artificial classification like that of Linnæus, must always conduce to this result, and the ease with which plants can be named by such a method, is in itself an evil rather than an advantage. When we advance from an empirical to a natural system, in which the diagnoses of the orders depend on a variety of characters, some of them connected with minute details of structure, the gain, both to the learner and teacher, is immense. The learner is compelled to begin at the root of the matter, and to acquaint himself with the structure and physiological function of every separate organ, and with the different forms it may assume, before he attempts to name a plant; and the teacher can no longer cram his class with that showy surface knowledge which is the bane of popular science teaching. The general adoption of the Natural system of classification was followed by a great fallingoff in the ranks of amateurs. The number of real students of botany is now however, we hope, increasing day by day, and the substantial interest and instruction derived from the science are in proportion enormously augmented.

The difficulties of the Natural system must be familiar to all teachers; probably every lecturer has more than 